\title{
The Effects of Soxhlet and Power Ultrasonic-Assisted Soxhlet Extraction on the Yield of Terpenoids Extract from Jasminum
} sambac

\author{
Nasrul Fikry Che Pa, Teh Jian Hong, Syeed Saifulazry Osman Al Edrus and Siti Khatini Abd \\ Talib
}

\begin{abstract}
This work is about the effect of two extraction methods namely Soxhlet extraction and power ultrasonic-assisted Soxhlet extraction (PUASE) to extract terpenoids from Jasminum sambac. The extraction parameters on yield of terpenoids for Soxhlet extraction are solvent composition $(25 \%, 50 \%, 75 \%$ and $100 \%$ methanol) and extraction time (6, 9 and $12 \mathrm{~h})$, while for PUASE, the parameter are ultrasonic amplitude $(25 \%, 50 \%$ and $75 \% ; 700 \mathrm{~W}, 20 \mathrm{kHz})$ and exposure time $(15,30$ and $45 \mathrm{~min})$, respectively. The solid-to-solvent ratio is set to 1:10. The overall time used in PUASE is set according to the time of Soxhlet extraction that produced maximum yield of terpenoids which is 12 hours and Power ultrasonic were used as a pre-treatment. The extracted essential oil containing terpenoids is qualified by Fourier-Transform infrared spectroscopy (FTIR) and quantified by Ultraviolet-Visible spectroscopy (UV-Vis) at 608nm wavelength via vanilin- $\mathrm{H}_{2} \mathrm{SO}_{4}$ method. PUASE shows increase yield of terpenoids produced up to $63 \%$ compared to Soxhlet extraction with 15 minutes of pre-treatment. This is suggested due to initial pre-treatment with power ultrasonic causes rupture to cell wall structure which explain the increased amount of terpenoids extracted. In this regards, the effect of both Soxhlet extraction and PUASE for extracting terpenoids is discussed.
\end{abstract}

Index Terms: Soxhlet, Power Ultrasonic-assisted Soxhlet Extraction, Jasminum sambac, Terpenoids

\section{INTRODUCTION}

In this study, Soxhlet extraction and power ultrasonic-assisted Soxhlet extraction (PUASE) are used to extract the essential oil containing terpenoids from Jasmine flower. The essential oil is analysed by FTIR and UV-Vis after the extraction process to qualify and quantify the presence of terpenoids. Terpenoids are used for clinical

Revised Manuscript Received on July 05, 2019

Ts. Dr. Nasrul Fikry Che Pa, Department of Chemical Engineering Technology, Faculty of Engineering Technology, Universiti Tun Hussein Onn Malaysia, 84600 Pagoh, Johor Darul Takzim, Malaysia. Corresponding author.Email: nfikry@uthm.edu.my

Teh Jian Hong, Department of Chemical Engineering Technology, Faculty of Engineering Technology, Universiti Tun Hussein Onn Malaysia, 84600 Pagoh, Johor Darul Takzim, Malaysia

Dr. Syeed Saifulazry Osman Al Edrus Laboratory of Biocomposite Technology, Institute of Tropical Forestry and Forest Products (INTROP), Universiti Putra Malaysia, 43400 UPM Serdang, Selangor Darul Ehsan, Malaysia

Siti Khatini Abd Talib, Department of Chemical Engineering Technology, Faculty of Engineering Technology, Universiti Tun Hussein Onn Malaysia, 84600 Pagoh, Johor Darul Takzim, Malaysia purposes as anticancer agents in India and China [1] as well as mosquito repellent [2]. Methanol is used in Soxhlet extraction and PUASE as a solvent to isolate the essential oil from Jasminum sambac. Terpenoids is extracted from the Jasminum sambac according to the solvent polarity. Polar solvent extract polar chemical component and vice versa. Besides, the amount of terpenoids extracted from the Jasminum sambac varied at different concentration of the solvent used as well as the parameters of the extraction e.g. time of extraction. The method of extraction is a very significant factor in the isolation of essential oil from Jasminum sambac as different extraction method results in different amount of essential oil extracted. The effect of different extraction method namely Soxhlet extraction and Power Ultrasonic-assisted extraction (PUASE) and varied parameter of extraction is explored in the study. Power ultrasonic probe sonicator is used to generate low frequency high power $(20 \mathrm{kHz}, 700$ watt) ultrasonic wave in this study as a pre-treatment for the sample prior extraction process. Power ultrasonic causes cavitation that damage the cell wall structure of the flower, thus during the Soxhlet extraction the essential oil is easier to be extracted from the Jasmine flower through the damaged cell wall structure.

Soxhlet extraction involves the leaching process which is a separation process to remove soluble substance from a solid using suitable solvent. Polarity of the solvent used could affects the efficiency of the extraction process and the final product extracted from the solid material [3]. Terpenoids is known as a polar chemical compound, therefore methanol is selected in this study as it shows high polarity in conjunction with targeted compound, thus it is readily soluble [4]. Other than the polarity of the solvent, parameter like time of extraction and the composition of the solvent also known to affect the extraction process efficiency. Increase time of extraction results in increase yield of sample extracted due to longer contact time favoured mass transfer until it reaches equilibrium [5]. In term of solvent composition, increase in volume fraction of the solvent mixture does not necessarily gives positive effect in the extraction yield as it vary as a function of solvent fraction [6]. The binary solvent extraction which used the solvent mixture containing solvent and water is more efficient than mono-solvent extraction which do not has water fraction, due to its polarity [6].

The PUASE is the combination of two extraction

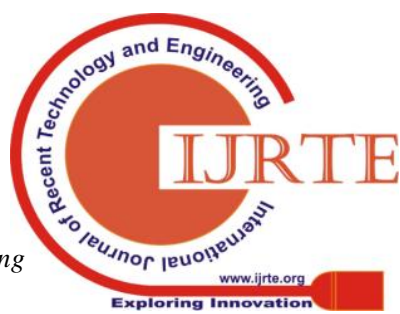




\section{The Effects of Soxhlet and Power Ultrasonic-Assisted Soxhlet Extraction on the Yield of Terpenoids Extract from Jasminum sambac}

technologies where one of the extraction methods is the power ultrasonic extraction. Power ultrasonic extraction is the removal and recovery of organic compounds from a permeable solid matrix using sound energy in high frequency [7]. The equipment which adopted the ultrasonication principle is the power ultrasonic probe sonicator system. The power ultrasonic probe sonicator system consists of a generator, an ultrasonic processor, upper horn element, and a detachable horn [8]. The schematic diagram of the ultrasonic bath is shown in Fig. 1.

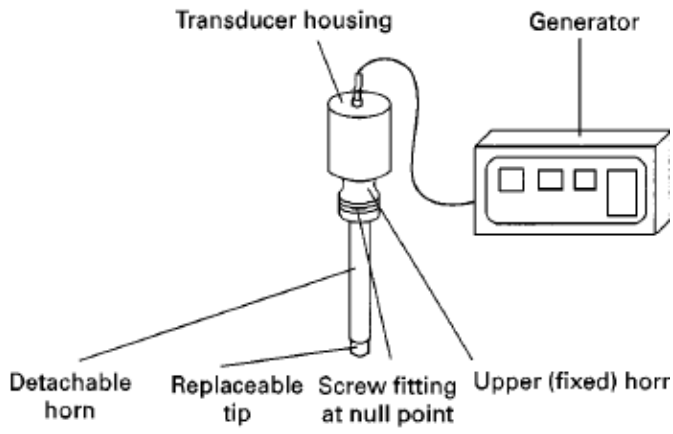

Fig. 1: Schematic diagram of probe-type sonicator. Source: (Bendicho \& Lavilla, 2016)

The ultrasonic exposure time and amplitude are considered as the main significant variables in the power ultrasonic-assisted extraction (PUASE) process. Fuad and co-workers in their work on extraction of oil from calophyllum inophyllum seeds found that prolonged ultrasonic exposure time leads to increase yield of oil extracted [9]. This is suggested due to higher level of seed cracking which lead to better solvent penetration into the cells and facilitating the release of oil from the cells into the solvent. However, exceeding certain threshold leads to detrimental effect on the yield, in their case, re-adsorption of the oil by the seed to maintain a dynamic equilibrium.

Recent study by Hashemi and co-workers in their work on effect of amplitudes ultrasound-assisted solvent extraction and pre-treatment time on the yield and quality of Pistacia Khinjuk Hull oil suggested that as the ultrasonic amplitude percentage increases, the yield of the extract also increases [10]. They found that increasing the amplitude from $25 \%$ to $50 \%$ of a $100 \mathrm{~W}, 30 \mathrm{kHz}$ power ultrasonic extraction increased the yield of $\alpha$-tocopherol extracted from $41.1 \mathrm{mg} / \mathrm{kg}$ to $50.36 \mathrm{mg} / \mathrm{kg}$, more than $20 \%$ increment which deem significant.

Findings by Goula in a study to extract pomegranate seed oil via ultrasound assisted extraction suggest that the ultrasonic wave could disrupt the cell walls structure, therefore larger contact area between solvent and material is created and more oil is appeared on the surface [11]. Yet, this effect would be increasingly weak on the inner cell walls as the distance is increased. Thus, the ultrasonic waves affect the mass transfer rate mainly in the solvent penetration stage. The amplitude of the power ultrasonic is related to the distance where the power ultrasonic sound waves could be transferred. The increase in the amplitude of the power ultrasonic resulted in the farther distance of its penetration coverage. It leads to increase number of broken cell walls structure and resulting in increase of extract yield. The use of power ultrasonic-assisted extraction offers some advantages in terms of improvement in the yield, bioactive compounds extraction with effects in the antioxidant and antimicrobial activities, reduction in the thermal degradation of compounds, reduction in time to extract the products, making the essential oil extraction cheaper and environmentally friendly [12].

\section{MATERIALS AND METHODOLOGY}

\subsection{Materials \& Chemicals Reagent}

Methanol was purchased from $\mathrm{HmbG}^{\circledR}$ Chemicals. Standard terpenoids solution was purchased from Sigma-Aldrich Corporation. Vanillin powder was purchased from GAMMA Scientific Research Sdn Bhd and concentrated sulphuric acid was purchased from RCI Labscan. Distilled water was prepared in the laboratory. The materials used were Jasminum sambac flower that was purchase from Indonesia, filter paper purchased from Whatman ${ }^{\circledR}$, silica gel purchased from Tesco stores (M) Sdn. Bhd, and thimble was obtained from Chemical Engineering Technology laboratory UTHM.

\subsection{Preparation of Jasminum Sambac}

The Jasminum Sambac flower was washed with distilled water to remove impurities on the surface of the flower petals. The flower petal sample is mainly used in the extraction process. The cleaned flower petals were put into the drying oven at $50{ }^{\circ} \mathrm{C}$ until a constant dry weight is obtained to ensure it was dried. After the flower petal was completely dry, it was ground into smaller pieces at $1 \mathrm{~mm}$ by using grinder. This is to increase the contact surface area of the flower petal with the solvent in the extraction process. The sample is stored in airtight container.

\subsection{Soxhlet Extraction}

Soxhlet extractor was used to extract the essential oil from jasmine flower. The dry jasmine flower petal samples are weighed according to the solid-to-solvent ratio and transferred into the Soxhlet thimble. The solvent used are varied $(25 \%, 50 \%, 75 \%$, and $100 \%$ methanol). $250 \mathrm{~mL}$ of solvent is transferred into the solvent flask at the bottom of the Soxhlet extractor. The extraction processes were conducted for 6,9 , and $12 \mathrm{~h}$. After the extraction, the extracts were filtered and dried at $35{ }^{\circ} \mathrm{C}$ under vacuum condition using rotary evaporator to remove the remaining solvent. The remaining extracts are stored in labelled reagent bottle under $4{ }^{\circ} \mathrm{C}$ to prevent the oxidization of essential oil when exposed to light and extend the shelf life of the essential oil.

\subsection{Power Ultrasonic-Assisted Soxhlet Extraction (PUASE)}

PUASE is the combination of power ultrasonic extraction and Soxhlet extraction. The PUASE was conducted with power ultrasonic probe sonicator at different amplitude $(25 \%, 50 \%$ and $75 \%)$ for 15,30 , and $45 \mathrm{~min}$. The extraction then was followed by Soxhlet extraction where the time of extraction were $11 \mathrm{~h} 45 \mathrm{~min}, 11 \mathrm{~h} 30 \mathrm{~min}$, and $11 \mathrm{~h} 15 \mathrm{~min}$, respectively, which make up the total PUASE time of 12 hours. The extraction time frame and the concentration of the solvent used in the PUASE extraction process are referred

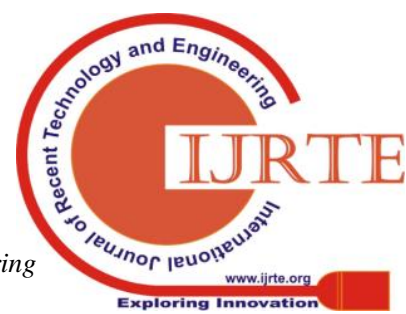


to the optimum conditions in the Soxhlet extraction. After the extraction was complete, the mixture was filtered and dried at $35{ }^{\circ} \mathrm{C}$ under vacuum condition. The extract then was mixed with acetone before stored in a sterile, airtight container under $4{ }^{\circ} \mathrm{C}$ and kept in dark environment to prevent the essential oil oxidized when exposed to light and increase the shelf life of the essential oil.

\subsection{Preparation of Standard Terpenoids Calibration Graph}

The standard terpenoids calibration graph was used to determine the terpenoids concentration in the extract by comparing the absorbance value. The standard terpenoids was diluted with distilled water at four different concentrations $(50,100,150$, and $200 \mathrm{mg} / \mathrm{g})$. The $2 \mathrm{ml}$ of the standard terpenoids was then mixed with $1 \mathrm{ml}$ of $2 \%$ vanillin reagent that was prepared by dissolving $2 \mathrm{~g}$ of vanillin powder into $100 \mathrm{ml}$ of concentrated sulphuric acid. The standard terpenoids-vanillin mixture was incubated for 20 $\min$ at $60{ }^{\circ} \mathrm{C}$ and cooled down to room temperature. Once the mixture was cooled down, it was analysed by UV-Vis spectrometer to determine the absorbance value. The graph of the absorbance value of the standard terpenoids-vanillin against the standard terpenoids concentration is plotted.

\subsection{Analysis by FTIR and UV-Vis}

Terpenoids was identified by UV-Vis spectrometer. UV- Vis was performed using $2 \%$ vanillin- $\mathrm{H}_{2} \mathrm{SO}_{4}$ solution that act as colouring reagent used to stain the extract based on the establish methods [13]. Preparation of $2 \%$ vanillin- $\mathrm{H}_{2} \mathrm{SO}_{4}$ reagent is by addition of $2 \mathrm{~g}$ of vanillin into $100 \mathrm{ml}$ of concentrated sulphuric acid. Referring to Suica-Bunghez and co-workers, $2 \mathrm{ml}$ of the extract was mixed with $1 \mathrm{ml}$ of the $2 \%$ vanillin- $\mathrm{H}_{2} \mathrm{SO}_{4}$ solution in cooling water [14]. The mixture was incubated at $60{ }^{\circ} \mathrm{C}$ for 20 minutes and cool to room temperature. After the mixture cooled, the absorbance was read at the wavelength of $608 \mathrm{~nm}$. Distilled water was added to dilute the extract prior mixing with $2 \%$ vanillin- $\mathrm{H}_{2} \mathrm{SO}_{4}$ reagent to avoid error reading in the UV-Vis due to over concentrated mixture. Additionally, the absorption or emission infrared spectrum of the sample was obtained by using Fourier-Transform infrared spectroscopy (FTIR). The possible chemical component in the extract was identified. From the results, the functional group of the possibly exist chemical component in the extract can be determined.

\section{RESULTS AND DISCUSSIONS}

The concentration of the total terpenoids content in the Jasminum sambac extract is determined by UV-Vis at the wavelength of $608 \mathrm{~nm}$. The absorbance of the extract-vanillin reagent mixture is referred to the terpenoids standard calibration graph to determine the concentration of the total terpenoids in the Jasminum sambac extract. The terpenoids concentration is stated as mg of terpenoids per gram of dried sample.

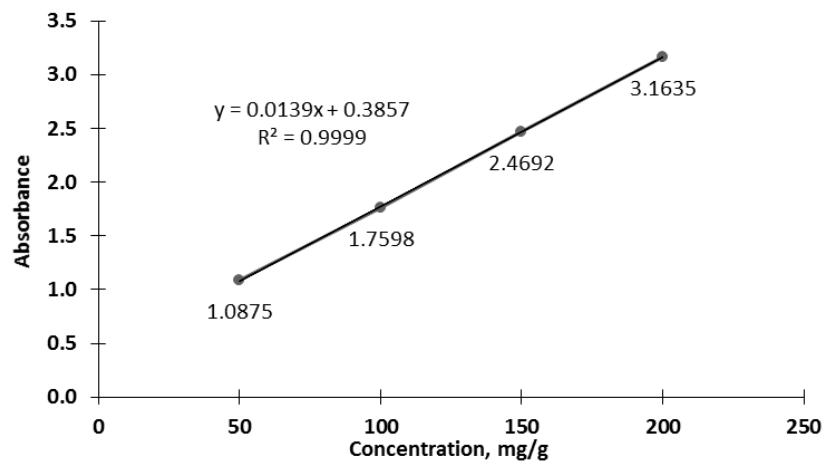

Fig. 2: Terpenoids calibration graph at $608 \mathrm{~nm}$ wavelength.

Fig. 2 shows the terpenoids calibration curve used in the determination of the total terpenoids content in the extract. The equation of the curve is shown in the graph in order to determine the concentration of the total terpenoids content in the Jasminum sambac extract when the absorbance value is not within the range of the curve. The total terpenoids concentration $(\mathrm{mg} / \mathrm{g})$ of the extract by Soxhlet extraction are shown in Table 1.

Table 1: Concentration of the total terpenoids $(\mathrm{mg} / \mathrm{g})$ in Jasminum sambac extract by Soxhlet extraction.

\begin{tabular}{|c|c|c|c|c|}
\hline \multirow{3}{*}{$\begin{array}{l}\text { Extraction } \\
\text { Time (h) }\end{array}$} & \multicolumn{4}{|c|}{ Solvent Composition (\%) } \\
\hline & 25 & 50 & 75 & 100 \\
\hline & \multicolumn{4}{|c|}{ Concentration of the total terpenoids $(\mathrm{mg} / \mathrm{g})$} \\
\hline \multirow[t]{2}{*}{6} & & 73.48 & 72.86 & 79.41 \\
\hline & $86.07 \pm 0.61$ & \pm 2.95 & \pm 0.76 & \pm 0.15 \\
\hline \multirow[t]{2}{*}{9} & 182.79 & 175.27 & 154.59 & 168.30 \\
\hline & \pm 3.10 & \pm 2.34 & \pm 6.26 & \pm 7.53 \\
\hline \multirow[t]{2}{*}{12} & 131.21 & 210.56 & 180.17 & 65.63 \\
\hline & \pm 1.17 & \pm 0.66 & \pm 1.42 & \pm 4.68 \\
\hline
\end{tabular}

From Table 1, it is shown that the highest concentration yield of terpenoids extracted from the Jasminum sambac is $210.56 \pm 0.66 \mathrm{mg} / \mathrm{g}$ using Soxhlet extraction time of 12 hours with $50 \%$ methanol-water solvent mixture.

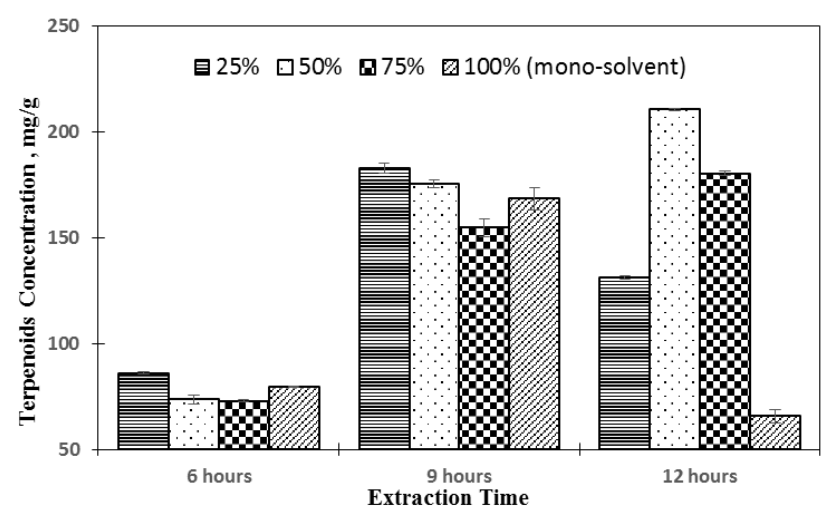

Fig. 3: Concentration of terpenoids $(\mathrm{mg} / \mathrm{g})$ extracted using binary solvent system at 6,9 and 12 hours of Soxhlet extraction.

Fig. 3 shows the concentration of terpenoids extracted using binary solvent system at 6,9 and 12 hours of Soxhlet extraction. In the binary solvent system, the percentages shown indicate the methanol composition in water. In the extraction using $50 \%$ and $75 \%$ methanol, as the extraction

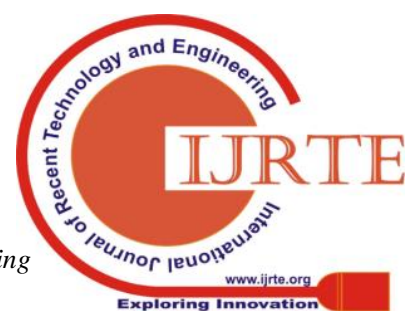




\section{The Effects of Soxhlet and Power Ultrasonic-Assisted Soxhlet Extraction on the Yield of Terpenoids Extract from Jasminum sambac}

time increases, the concentration of terpenoids increases. This trend can be explained by longer extraction time allows more terpenoids to diffuse from the solid material into the solvent until it reaches equilibrium [15]. However, the concentration of terpenoids decreases when the extraction time increased from 9 hours to 12 hours using $25 \%$ and $100 \%$ methanol. This might be due to the loss of antioxidant along with time following the exposure of the terpenoids to air [16]. This can cause easily oxidation of terpenoids when exposed to air [17]. In addition, the higher the water content in the methanol-water solution, the higher the boiling point of the solution [18]. At 25\% methanol-water mixture, $75 \%$ of the solution is made up of water. Yang and co-workers in their work concluded that the temperature of the solution has effect on the terpenoids stability in the water [19]. The terpenoids stability decreases as the temperature increases. According to Arrhenius equation, higher temperature increases the rate of reaction. In addition, Van't Hoff law stated that the temperature increased in $10{ }^{\circ} \mathrm{C}$ double the rate of reaction [18]. The rate of oxidation reaction of terpenoids in the Jasminum sambac extract increases due to higher temperature of the solvent mixture.

Referring to Fig. 3, it is shown that at six hours and nine hours of Soxhlet extraction, the concentration of terpenoids decreased gradually from $25 \%$ to $75 \%$ of solvent composition, then increased when $100 \%$ methanol is used. At 12 hours of extraction, the highest terpenoids concentration is obtained when $50 \%$ methanol as solvent is used at 12 hours of extraction. The increment in solvent composition from $50 \%$ to $100 \%$ gradually decreased the concentration of terpenoids extract in prolonged extraction time. In the study, the mono solvent system did not extract the highest amount of terpenoids. This is suspected caused by the higher effectiveness of the binary solvent system compared to mono-solvent system in the extraction of terpenoids due to the solvent mixture polarity and the solubility of terpenoids in the solvent mixture [6].

Table 2: Concentration of the total terpenoids in Jasminum sambac extract PUASE.

\begin{tabular}{|c|c|c|c|c|c|}
\hline \multirow{3}{*}{$\begin{array}{c}\text { Solvent } \\
\text { Composition }\end{array}$} & \multirow{3}{*}{$\begin{array}{l}\text { PUASE } \\
\text { Time }\end{array}$} & \multirow{3}{*}{$\begin{array}{c}\text { Soxhlet } \\
\text { Time }\end{array}$} & \multicolumn{3}{|c|}{$\begin{array}{l}\text { Power Ultrasonic } \\
\text { Amplitude }\end{array}$} \\
\hline & & & $25 \%$ & $50 \%$ & $75 \%$ \\
\hline & & & \multicolumn{3}{|c|}{$\begin{array}{r}\text { Concentration of } \\
\text { terpenoids }(\mathrm{mg} / \mathrm{g})\end{array}$} \\
\hline \multirow{5}{*}{$\begin{array}{c}50 \% \\
\text { methanol-water }\end{array}$} & $15 \mathrm{~min}$ & $\begin{array}{c}11 \mathrm{~h} \\
45 \mathrm{~min}\end{array}$ & $\begin{array}{l}257.66 \\
\pm 1.02\end{array}$ & $\begin{array}{l}343.27 \\
\pm 0.51\end{array}$ & $\begin{array}{r}262.16 \\
\pm 2.29\end{array}$ \\
\hline & \multirow{2}{*}{$30 \mathrm{~min}$} & $11 \mathrm{~h}$ & 189.86 & 231.76 & 275.11 \\
\hline & & $30 \mathrm{~min}$ & \pm 0.76 & \pm 2.04 & \pm 1.27 \\
\hline & \multirow{2}{*}{$45 \mathrm{~min}$} & $11 \mathrm{~h}$ & 292.55 & 291.66 & 143.45 \\
\hline & & $15 \mathrm{~min}$ & \pm 0.51 & \pm 1.78 & \pm 3.31 \\
\hline
\end{tabular}

Table 2 shows the concentration of the terpenoids in Jasminum sambac extract by PUASE. The highest concentration of terpenoids extracted via PUASE is $343.27 \pm 0.51 \mathrm{mg} / \mathrm{g}$ at $50 \%$ amplitude $(700 \mathrm{~W}, 20 \mathrm{kHz})$ and 15 minutes of power ultrasonic exposure. The concentration of terpenoids increased up to $63 \%$ through PUASE compared with conventional Soxhlet extraction process. The total extraction time, and the solvent composition are selected based on the condition of the maximum terpenoids extracted in conventional Soxhlet extraction which is 12 hours of extraction using 50\% methanol-water solvent mixture. The cavitation process caused by the power ultrasonic imploding bubbles on the surface of solid material resulting in breaking down of its cell wall structure. Therefore leading to the improved penetration of liquid through the cell membrane [20].

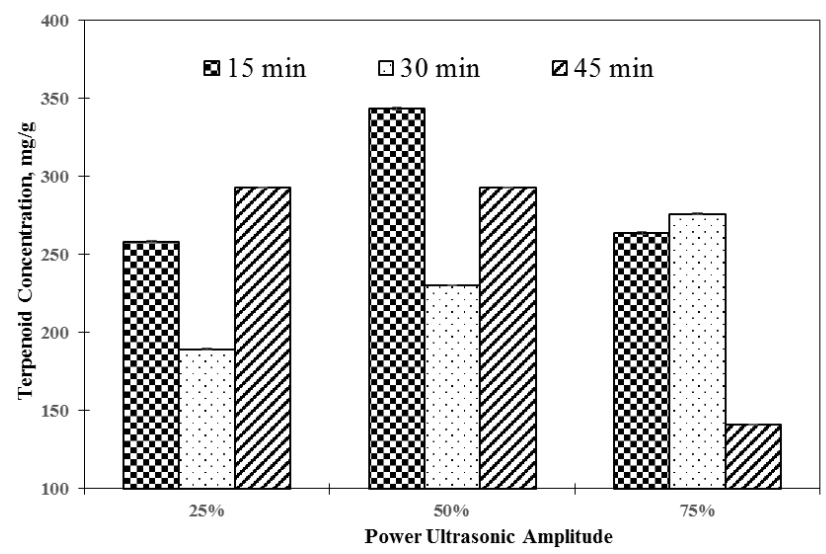

Fig. 4: Concentration of terpenoids extract by PUASE.

From Fig. 4, the highest concentration of terpenoids in the Jasminum sambac extracted via PUASE is at 15 minutes of $50 \%$ ultrasonic amplitude treatment. At the pre-treatment time of 30 minutes, the yield of terpenoids increases as the power ultrasonic amplitude increases. The situation is suspected caused by the ultrasonic cavitation during the PUASE. The cavitation disrupted the membranes cell and cell walls structure of the solid material [10]. When power ultrasonic wave travels through the solvent, it will results in a series of compression and rarefaction. At sufficiently high power, the rarefaction exceeds the attractive forces between molecules in a liquid phase, which subsequently causes the formation of cavitation bubbles. The increase in the amplitude creates more violent bubbles collapse. This increases the cavitation in the solvent which leads to greater membrane and cell wall disruption [20]. As a result, the extraction process is improved where the terpenoids can be released into the solvent easier during Soxhlet extraction.

At 15 minutes of $25 \%$ power ultrasonic amplitude pre-treatment, the yield of terpenoids increased from $25 \%$ to $50 \%$, but it decreased at $75 \%$ of power ultrasonic amplitude. At higher power ultrasonic amplitude, the cavitation produce more violent bubble collapse which is associated with more hot spots during the explosion of bubbles. Some of the terpenoids is degraded due to the high local temperature and pressure [21]. The temperature affects the compound solubility, solvent diffusion rate, mass transfer rate, and etc. during the extraction process. Higher temperature increases the mass transfer of the terpenoids into the solvent during the extraction process but at the same time it also promotes higher degradation rate of the terpenoids. It becomes more obvious when the temperature exceed $75{ }^{\circ} \mathrm{C}$ [20]. At $75 \%$ power ultrasonic amplitude, the increase in the pre-treatment time reduced the concentration of terpenoids in the extract. The concentration of terpenoids increased from 15 minutes to 30 minutes then decreased at 45 minutes of PUASE time. During PUASE, the prolonged exposure time is suspected to 
favour the reabsorption of the terpenoids into the solid [22]. Thus, the trend for $75 \%$ power ultrasonic amplitude suggested that prolong exposure exceeding 30 minutes resulted in the reabsorption of the terpenoids.

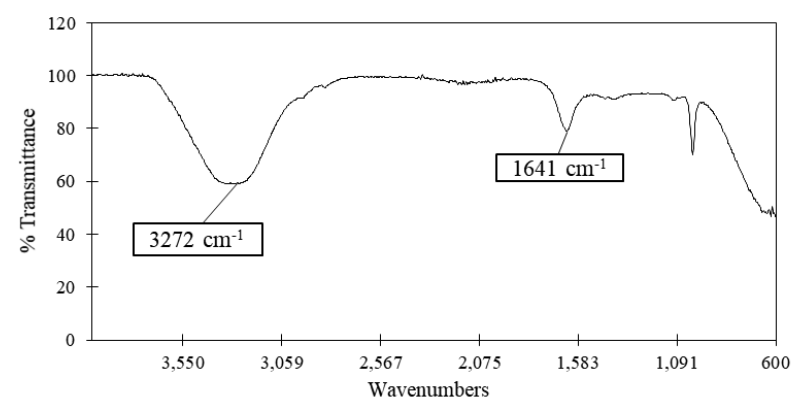

Fig. 5: FTIR spectrum of Jasminum sambac extract using conventional Soxhlet extraction.

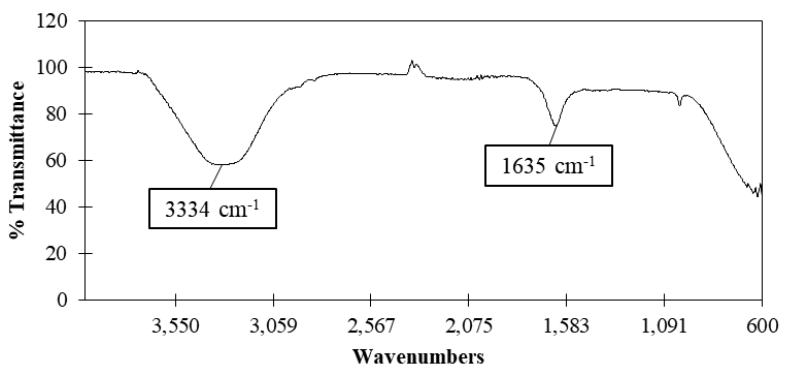

Fig. 6: FTIR spectrum of Jasminum sambac extract using PUASE.

The FTIR spectrum of methanolic extract of Jasminum sambac by conventional Soxhlet extraction and PUASE are shown in Fig. 5 and Fig. 6 respectively. From the FTIR spectrum, the peak read by the FTIR is similar in both figures. According to Vanaja [23], the presence of $\mathrm{C}-\mathrm{H}$ stretch bond, $\mathrm{O}-\mathrm{H}$ stretch bond, and $\mathrm{C}=\mathrm{O}$ stretch bond indicate the presence of terpenoids, saponins and phenols in the extract. From Figure 5 and 6, there is a wide peak at 3500 $\mathrm{cm}^{-1}$ to $3300 \mathrm{~cm}^{-1}$. In this peak, the hydroxyl group $(\mathrm{O}-\mathrm{H}$ stretch bond) is present. The hydroxyl functional group is present at $3272 \mathrm{~cm}^{-1}$ in Soxhlet extraction whereas in PUASE it is present at $3334 \mathrm{~cm}^{-1}$. This indicates the presence of alcohol functional group as well as terpenoids in the extract. According to Boughendjioua and Djeddi [24], the broad $\mathrm{O}-\mathrm{H}$ stretch bond at $\sim 3400 \mathrm{~cm}^{-1}$ and $\mathrm{C}=\mathrm{O}$ stretch bond at $\sim 1700 \mathrm{~cm}^{-1}$ shows the presence of oxo-group $(=\mathrm{O})$ also reveals the presence of terpenoids in the extract. Fig. 5 suggests the presence of oxo functional group at $1641 \mathrm{~cm}^{-1}$ in Soxhlet extraction and Fig. 6 suggests the presence of oxo functional group at $1635 \mathrm{~cm}^{-1}$.

\section{CONCLUSIONS}

The effectiveness of the conventional Soxhlet extraction and the PUASE under various process parameters are investigated. In Soxhlet extraction, the maximum concentration of terpenoids is extracted under 12 hours of extraction time, using 50\% methanol as solvent, and 1:10 solid-to-solvent ratio. The maximum yield extracted is $210.56 \pm 0.66 \mathrm{mg} / \mathrm{g}$. In the PUASE, the maximum concentration of terpenoids which is $343.27 \pm 0.51 \mathrm{mg} / \mathrm{g}$ is extracted using $50 \%$ power ultrasonic amplitude and
15 minutes of power ultrasonic pre-treatment. The PUASE extracted higher concentration of terpenoids from the Jasminum sambac compared to the conventional Soxhlet extraction method. Thus, this shows that PUASE has higher efficiency of extraction compared to Soxhlet extraction.

\section{ACKNOWLEDGMENT}

This work is supported by Universiti Tun Hussein Onn Malaysia under TIER 1 Grant Scheme (Vot: H084).

\section{REFERENCES}

1. Thoppil, R. J., \& Bishayee, A.Terpenoids as potential chemopreventive and therapeutic agents in liver cancer, 3(9), (2011).228-249.

2. Norris, E. J., \& Coats, J. R. Current and Future Repellent Technologies: The Potential of Spatial Repellents and Their Place in Mosquito-Borne Disease Control. (2017), http://doi.org/10.3390/ijerph14020124

3. Voon, H. C., Bhat, R., \& Rusul, G. Flower extracts and their essential oils as potential antimicrobial agents for food uses and pharmaceutical applications. Comprehensive Reviews in Food Science and Food Safety, 11(1), (2012) 34-55. http://doi.org/10.1111/j.1541-4337.2011.00169.X

4. Ye, Q., Jin, X., Zhu, X., Lin, T., Hao, Z., \& Yang, Q. An Efficient Extraction Method for Fragrant Volatiles from Jasminum sambac (L.) Ait. Journal of Oleo Science, 64(6), (2015) 645-52. http://doi.org/10.5650/jos.ess15014

5. Baldosano, H. Y., Beatriz, M., Castillo, M. G., Elloran, C. D. H., \& Bacani, F. T. (2015). Effect of Particle Size, Solvent and Extraction Time on Tannin Extract from Spondias purpurea Bark Through Soxhlet Extraction, 3, 4- 9 .

6. Dent, M., Dragovi, V., Peni, M., \& Bm, M. (2013). The Effect of Extraction Solvents, Temperature and Time on the Composition and Mass Fraction of Polyphenols in Dalmatian Wild Sage ( Salvia officinalis L.) Extracts, 9862(1), $84-91$

7. Webster, G. R. B. Soxhlet and Ultrasonic Extraction of Organics in Solids Encyclopedia of Analytical Chemistry, (2006). 1-13. http://doi.org/10.1002/ 9780470027318.a0864

8. Bendicho, C., \& Lavilla, I. (2016). Extraction|Ultrasound Extractions. In Reference Module in Chemistry, Molecular Sciences and Chemical Engineering (pp. 1448-1454). Vigo, Spain: Academic Press.

9. Fuad, F. M., \& Don, M. M. (2016). Ultrasonic-assisted extraction of oil from calophyllum inophyllum seeds: Optimization of process parameters. Jurnal Teknologi, 78(10), 199-206. http://doi.org/10.11113/jt.v78.4946

10. Hashemi, S. M., Khaneghah, A. M., \& Akbarirad, H. The effects of amplitudes ultrasound-assisted solvent extraction and pretreatment time on the yield and quality of Pistacia Khinjuk hull oil. Journal of Oleo Science, 65(9), (2016). 733-738. http://doi.org/10.5650/jos.ess 15252

11. Goula, A. M. Ultrasound-assisted extraction of pomegranate seed oil Kinetic modeling. Journal of Food Engineering, 117(4), (2013) 492-498. http://doi.org/10.1016/j.jfoodeng.2012.10.009

12. Michelon, F., Nora, D., \& Borges, C. D. (2017). Ultrasound pretreatment as an alternative to improve essential oils extraction. Food Technology, 47(9), 1-9.

13. Das, M. (2015). Extraction, Phytochemical Analysis, Isolation and Biological Activities of the Leaves of Ipomoea eriocarpa using Various Solvents.

14. Suica-Bunghez, I. R., Teodorescu, S., Dulama, I. D., Voinea, O. C., Imionescu, S., \& Ion, R. M. Antioxidant activity and phytochemical compounds of snake fruit (Salacca Zalacca). IOP Conference Series: Materials Science and Engineering, 133(1). (2016) http://doi.org/10.1088/1757-899X/133/1/012051

15. Predescu, C., Papuc, C., Nicorescu, V., Gajaila, I, Goran, G, Daniela Petcu, C., \& Stefan, G. (2016). The Influence of Solid-to-Solvent Ratio and Extraction Method on Total Phenolic Content, Flavonoid Content and Antioxidant Properties of Some Ethanolic Plant Extracts. Revista de Chimie -Bucharest- Original Edition-, 67(10), 1922-1927.

16. Wong, Y. H., Lau, H. W., Tan, C. P., Long, K., \& Nyam, K. L (2014). Binary Solvent Extraction System and Extraction Time Effects on Phenolic Antioxidants from Kenaf Seeds (Hibiscus cannabinus L.) Extracted by a

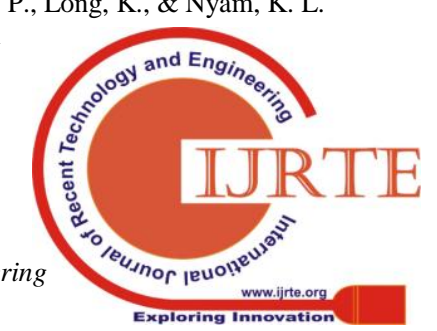




\section{The Effects of Soxhlet and Power Ultrasonic-Assisted Soxhlet Extraction on the Yield of Terpenoids Extract from Jasminum sambac}

Pulsed Ultrasonic-Assisted Extraction, 2014.

17. Andersen, K. E., Bruze, M., Johansen, J. D., Arnau, A. G., Goh, C., Nixon, R., \& White, I. R. Air-oxidized linalool - a frequent cause of fragrance contact allergy Johanna $\mathrm{Br}$ ared, (4), (2012) 1- 13. http://doi.org/10.1111/j.1600-0536.2012.02134.x

18. Turek, C., \& Stintzing, F. C.. Stability of Essential Oils : A Review. Food Science and Food Safety, 12, (2013). 40-53. http://doi.org/10.1111/1541-4337.12006

19. Yang, Y., Kayan, B., Bozer, N., Pate, B., Baker, C., \& Gizir, A. M. Terpene degradation and extraction from basil and oregano leaves using subcritical water. Journal of Chromatography A, 1152(1-2), (2007) 262-267. http://doi.org/10.1016/j.chroma.2006.11.037

20. Medina-Torres, N., Ayora-Talavera, T., Espinosa-Andrews, H., Sánchez-Contreras, A., \& Pacheco, N. Ultrasound Assisted Extraction for the Recovery of Phenolic Compounds from Vegetable Sources. Agronomy, 7(3), (2017) 47. http://doi.org/10.3390/agronomy7030047

21. Yeong, Y.L., Pang, S. F., Chong, S. Y., \& Gimbun, J. (2018). Comparison of Microwave and Ultrasonic Assisted Extraction of Kaempferol from Cassia Alata, 7,84-89.

22. Rincón, B., Bujalance, L., Fermoso, F. G., Martín, A., \&Borja, R.. Effect of ultrasonic pretreatment on biomethane potential of two-phase olive mill solid waste: Kinetic approach and process performance. Scientific World Journal, 2014. http://doi.org/10.1155/2014/648624

23. Vanaja, D. (2016). A Study on Phytochemicals, Antioxidant Activity and Ft-Ir Analysis of Rhapis Excelsa (Thunb.) a. Henry. European Journal of Pharmaceutical and Medical Research, 3(7), 390-394.

24. Boughendjioua, H., \& Djeddi, S. (2017). Fourier Transformed Infrared Spectroscopy Analysis of Constituents of Lemon Essential Oils from Algeria, 5(3), 30-35.

http://doi.org/10.11648/j.ajop.20170503.12

\section{AUTHORS PROFILE}

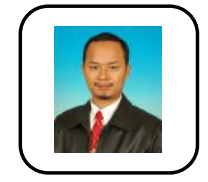

Nasrul Fikry Che Pa is a lecturer from Faculty of Engineering Technology, Universiti Tun Hussein Onn Malaysia. His area of research interest includes extraction technology, ultrasonication, separation process and activated carbon. To date, he registered a patent on ultrasonication invention as well as published few scientific articles that includes journal, proceedings and book chapter in regards to his research interest.

Teh Jian Hong is a student from Faculty of Engineering Technology, Universiti Tun Hussein Onn Malaysia. Currently, he is completing his Bachelor Degree of Chemical Engineering Technology (Biotechnology) with honours.

Syeed Saifulazry Osman Al Edrus is a research officer from Institute of Tropical Forestry and Forest Products, Universiti Putra Malaysia, majoring in nanocomposite science. To date, he has published more than 20 articles in numerous journals, book chapters, proceedings etc.

Siti Khatini Abd Talib is a student from Faculty of Engineering Technology, Universiti Tun Hussein Onn Malaysia. Currently, he is completing his Bachelor Degree of Chemical Engineering Technology (Biotechnology) with honours. 